\title{
Os efeitos negativos causados pela construção e operação de usinas hidrelétricas
} The negative effects caused by the construction and operation of hydroelectric plants

\section{Los efectos negativos causados por la construcción y operación de plantas}

\section{hidroeléctricas}

Recebido: 12/12/2019 | Revisado: 28/01/2020 | Aceito: 18/05/2020 | Publicado: 26/05/2020

\section{Ramon de Souza Ferreira}

ORCID: http://orcid.org/0000-0002-1629-1741

Universidade Federal dos Vales do Jequitinhonha e Mucuri, Brasil

E-mail: marromsf@hotmail.com.br

\section{Resumo}

Tratar de questões relacionadas a formas de obtenção e transformação de energia tem sido polêmicas desde o início desses processos. Várias são as formas que cada país trabalha em busca de aumentar sua oferta energética. Cada tipo de geração de energia demanda estudo e causa pelo menos algum tipo de impacto ambiental podendo ser mais nocivo ou não. $\mathrm{O}$ objetivo desse trabalho foi tratar das questões energéticas do Brasil e citar os impactos mais comuns causados pela busca por produção de energia como, por exemplo, inundação de grandes áreas, realocação de famílias e animais das áreas que serão inundadas, represamento dos rios, mas focando principalmente em um dos que pode ser o pior impacto que é a geração de gases do efeito estufa em represas de usinas hidrelétricas e que não contabilizados nesse tipo de empreendimento. Foi utilizada para a confecção desse artigo a técnica de pesquisa bibliográfica, onde objetiva estudar a fundo uma questão pré-definida e atualizá-la a fim de tornar o trabalho o mais recente possível, trazendo ainda as questões mais importantes relativas ao tema de forma mais compacta. Como conclusão, ficou evidenciado que mesmo não sendo analisado em profundidade, os efeitos negativos das usinas hidrelétricas precisam ser estudados com mais cautela de forma que possam ser minimizados. Esses efeitos também precisam ser colocados no momento da escolha da construção de uma nova geradora de energia em detrimento a outra, pois, os países já estão alterando suas matrizes energéticas em busca de maior eficiência e proteção ao meio ambiente.

Palavras-chave: Energia; Impacto ambiental; Efeito estufa; Usinas hidrelétricas. 


\section{Abstract}

Addressing issues related to ways of obtaining and transforming energy has been controversial since the beginning of these processes. There are several ways that each country works in search of increasing its energy supply. Each type of power generation requires study and causes at least some type of environmental impact, which may be more harmful or not. The objective of this work was to address energy issues in Brazil and to mention the most common impacts caused by the search for energy production, such as the flooding of large areas, relocation of families and animals in the areas to be flooded, damming of the rivers, but mainly focusing in one of the worst impacts, which is the generation of greenhouse gases in hydroelectric power plant dams and which are not accounted for in this type of enterprise. The bibliographic research technique was used for the preparation of this article, where it aims to study in depth a pre-defined question and update it in order to make the work as recent as possible, while also bringing the most important questions related to the theme in a more compact. As a conclusion, it was evident that even if not analyzed in depth, the negative effects of hydroelectric plants need to be studied with more caution so that they can be minimized. These effects also need to be put in place when choosing to build a new energy generator in detriment to another, as countries are already changing their energy matrixes in search of greater efficiency and protection of the environment.

Keywords: Energy; Environmental impact; Greenhouse effect; Hydroelectric plants.

\section{Resumen}

Abordar los problemas relacionados con las formas de obtener y transformar la energía ha sido controvertido desde el comienzo de estos procesos. Hay varias formas en que cada país trabaja en busca de aumentar su suministro de energía. Cada tipo de generación de energía requiere estudio y causa al menos algún tipo de impacto ambiental, que puede ser más dañino o no. El objetivo de este trabajo fue abordar los problemas energéticos en Brasil y mencionar los impactos más comunes causados por la búsqueda de producción de energía, como la inundación de grandes áreas, la reubicación de familias y animales en las áreas que se inundarán, la represa de los ríos, pero principalmente en uno de los peores impactos, que es la generación de gases de efecto invernadero en las represas de centrales hidroeléctricas y que no se contabilizan en este tipo de empresa. La técnica de investigación bibliográfica se utilizó para la preparación de este artículo, donde tiene como objetivo estudiar en profundidad una pregunta predefinida y actualizarla para que el trabajo sea lo más reciente posible, al tiempo que presenta las preguntas más importantes relacionadas con el tema de una manera más 
compacto Como conclusión, era evidente que incluso si no se analiza en profundidad, los efectos negativos de las plantas hidroeléctricas deben estudiarse con más precaución para que puedan minimizarse. Estos efectos también deben aplicarse cuando se elige construir un nuevo generador de energía en detrimento de otro, ya que los países ya están cambiando sus matrices de energía en busca de una mayor eficiencia y protección del medio ambiente.

Palabras clave: Energía; Impacto ambiental; Efecto invernadero; Plantas hidroeléctricas.

\section{Introdução}

As questões que envolvem a construção de uma usina hidrelétrica vão além da simples modificação de um terreno e posterior alagamento do mesmo. De acordo com Colito (2000), a justificativa utilizada no Brasil para a instalação de uma nova usina hidrelétrica é baseada na grande oferta hídrica nacional e na possibilidade de conseguir melhorar o desenvolvimento econômico, social e político do país. Essa política energética se baseia na simples inundação e realocação de populações em outras áreas. Os maiores investimentos na construção de usinas hidrelétricas, como afirmar Derrosso \& Ichikawa (2014) ocorreram entre as décadas de 1960 e 1980. Nesse período o Brasil construiu mais de sessenta usinas e se tornou um dos maiores investidores em usinas de grandes proporções. Para Kuniyoshi (2009), nesse mesmo período que também corresponde ao período em que o Brasil vivia a ditadura militar, houve grande avanço na engenharia civil e diversas obras foram realizadas incluindo projetos de controle de enchentes, geração de energia, reservatórios e barragens.

De acordo com Müller (2003), as questões relativas à construção de usinas hidrelétricas no Brasil ainda devem compreender o baixo nível dos reservatórios brasileiros, a incerteza de um apagão, a possível diminuição das tarifas e as questões com o meio ambiente.

Para Lima (2014), é importante salientar que o Brasil é um grande produtor de energia através de hidrelétrica e a grande quantidade de água disponível no território nacional é fundamental para esse processo além de ser necessário compreender todo o processo histórico das usinas no país antes de pontuar os problemas ambientais decorrentes dessa atividade.

Para Wolfgang \& Mello (1990), levar em conta somente a grande capacidade de produção de energia como no caso da Bacia Amazônica não justifica a construção de usinas hidrelétricas deixando de lado questões negativas como os custos ecológicos e a longo prazo os custos econômicos que não são adequadamente relacionados sem contar que alguns empreendimentos causam tantos efeitos negativos que não são viáveis em hipótese nenhuma. Sendo assim, de acordo com Thaumaturgo, Simões \& Trannin (2013), o governo passou a 
investir também em usinas termoelétricas e de extração de petróleo.

Ao ser projetada uma usina hidrelétrica, é realizado um estudo de impacto ambiental (EIA) que procura pontuar todas as transformações que ocorrerá no meio ambiente e de alguma forma minimizar os efeitos negativos do empreendimento. Segundo Oliveira (2004), o estudo precisa pontuar todas as atividades realizadas no empreendimento de forma que possa caracterizar as que modificam o meio ambiente.

Soares (2009) cita que na construção da Usina Hidrelétrica de Candonga localizada nos limites entre os municípios de Rio Doce e Santa Cruz do Escalvado, no estado de Minas Gerais, Brasil, os estudos de impactos ambientais não levaram em conta os impactos sociais causados pela retirada das pessoas e realocação em outras regiões. Para Queiroz (2011), tais estudos não incluem os efeitos socioambientais causados na população e acabam entrando como ações mitigadoras e insatisfatórias. A comunidade apenas é transferida compulsoriamente causando ruptura social, alteração na forma de vida e alteração na cadeia alimentar da área circunvizinha à barragem.

De acordo com Muniz \& Santos (2012) têm ocorrido grandes impactos ambientais em consequência da instalação de novas usinas hidrelétricas. Para Bortoleto (2012), o setor elétrico nacional cresceu acreditando que os benefícios gerados iam ser tão grandes que os fatores negativos não teriam significância. Hoje é possível constatar o contrário.

Independente dos impactos causados pela construção de usinas hidrelétricas, a prioridade ainda é a construção de barragens para esse tipo de energia. Já se sabe que tal processo acarreta em grandes impactos ambientais e mesmo assim os resultados são mais favoráveis e os impactos devem ser tratados por meio de medidas mitigatórias como preservação e compensação (Silva et al., 2007). Para Siqueira \& Henkes (2014), a finalidade dos projetos deve ser com intuito de melhorar a vida da população, mas essa gestão deve iniciar juntamente com o início do projeto e continuar na fase da operação da usina.

Nesse contexto, o objetivo desse trabalho foi tratar das questões energéticas do Brasil e citar os impactos mais comuns causados pela busca por produção de energia.

\section{Usinas Hidrelétricas}

Para Rosa et al (1995), a energia elétrica proveniente de usinas hidrelétricas é a melhor opção para o Brasil nas questões técnicas, econômicas e ambientais em vista das outras. Sousa (2000) afirma que no período de construção da barragem ocorre grande impacto sobre o meio ambiente que pode ser estendido ao longo do tempo de vida do projeto e pode afetar no 
andamento da obra.

Segundo Didonet (2009), a maioria da energia produzida no Brasil é proveniente de usinas hidrelétricas que transformam energia potencial contida em represas em energia cinética que giram pás de turbinas produzindo energia elétrica ao acionar geradores. Por se tratar de um sistema que depende da continuidade da vazão do rio que passa pelas turbinas, a região se torna totalmente dependente de chuvas para manter o nível dos reservatórios e a usina funcionando.

Pena (2016) acrescenta que 90\% de toda energia gerada no país vem das hidrelétricas. As primeiras barragens foram construídas no Brasil a partir do final do século XIX, mas somente a partir da Segunda Guerra Mundial que o Brasil adotou como relevante esse tipo de produção de energia.

Para Junior (2010), todas as formas de geração de energia implicam em problemas ambientais e sociais e no caso das hidrelétricas esses problemas vão além de toneladas de concreto e, grandes áreas alagadas.

\section{Impactos Causados pela Construção e Operação de Usinas Hidrelétricas}

A construção de represas, para uso das águas em usinas hidrelétricas, afeta o meio ambiente de forma significativa, independente do porte da mesma e alteram desde o meio físico até o biótico, econômico e social e não só na área da represa, mas também em toda a jusante. Muitos são os problemas causados pela construção da represa como alteração na fauna e na flora, alteração no clima, problemas com a qualidade da água, alagamento de áreas produtivas, problemas com a navegabilidade do curso d'água, erosão e desmatamento das áreas inundadas.

Também existem os problemas sociais quando pessoas que moram nas áreas alagadas são obrigadas a se mudarem deixando suas terras e sendo obrigadas a se adaptarem a outras realidades. Segundo Didonet (2009), esses problemas puderam ser vistos durante a construção da hidrelétrica de Sobradinho quando ocorreu o represamento do Rio São Francisco no estado da Bahia.

O primeiro impacto ambiental causado é o corte de árvores para a construção dos canteiros de obras. Nesse momento a fauna também é afetada com a alteração do seu habitat. Após esse estágio a represa é construída e a área é alagada. Nesse segundo momento toda a vegetação da área do reservatório é submersa originando um tipo de limbo. Dependendo da quantidade e tipo da flora local, ela pode se desprender do solo inundado e influenciar no 
funcionamento das turbinas da usina. Após a inundação o ambiente é transformado em um grande lago (Paquete, 2016).

Outro fator que deve ser observado é em relação aos sedimentos. Segundo Júnior (2014), reservatórios que se localizam em áreas de grande erosão tendem a ter menor vida útil devido ao depósito de sedimentos em seu leito. A turbidez da água também tende a aumentar dificultando a fotossíntese e pode haver alteração no abrigo dos peixes, alimentação e local de desova. Para Carvalho (2000), a barragem diminui a velocidade do rio ocasionando numa maior deposição de material no leito do rio gerando assoreamento e diminuindo a capacidade de armazenamento da represa.

Müller (1995) afirma que quando ocorre o represamento do rio o excesso de pressão que essa água exerce influencia nas nascentes e nos processos de alimentação e descarga dos aquíferos próximos, mesmo os profundos. Esse processo pode fazer reaparecer antigos pântanos e lagos que outrora não existiam mais. Para Scheibe (2004), ainda existe a preocupação do aumento das águas dos reservatórios que podem influenciar na elevação no nível dos lençóis freáticos próximos às cidades e atingir cemitérios, fossas, inviabilizar poços e ainda em épocas de cheias serem forçados a abrirem comportas a fim de liberar água causando ainda mais impactos.

Sousa (2000) considera que os impactos físicos causados no meio são a diminuição na velocidade do rio, aumento de sedimentação, alteração na temperatura dividindo a represa em dois ambientes sendo um com a temperatura mais baixa (fundo do reservatório) e outro com a temperatura mais alta (superfície do reservatório) e ainda favorecendo o processo de eutrofização. Em relação aos impactos biológicos, a construção da represa ocasiona a separação do rio em dois ambientes causando o isolamento de espécies que outrora viviam em contato além de impedir a piracema.

Além disso, ainda existe a perda da qualidade da água e o aumento da incidência de doenças para os moradores vizinhos do reservatório. Nilton (2009) ainda cita outros problemas como a perda de heranças históricas e culturais, alterações nas atividades econômicas e usos tradicionais das terras, problemas de saúde pública e efeitos sociais negativos pela realocação de famílias.

Para Andrade (2010) todas alterações citadas anteriormente podem ter efeitos diretos ou indiretos e podem produzir efeitos e impactos cumulativos. Porém, ainda de acordo com Nilton (2009), a criação de uma usina hidrelétrica não tem apenas efeitos negativos. É necessário levar em conta também a geração de energia, a disponibilidade de água armazenada, possibilidade da criação de áreas de recreação, possibilidade da prática de 
aquicultura e aumento da possibilidade de postos de trabalho para os moradores da área.

Outro problema que pode ocorrer durante o ciclo de vida útil do reservatório é a eutrofização do mesmo. Essa grande concentração de nutrientes pode ocorrer devido ao baixo fluxo de água e à grande deposição de sedimentos em seu leito tornando impossível realizar a fotossíntese. Durante esse processo os fitoplânctons na maioria cianofíceas e as macrófitas aquáticas aparecem tornando a água imprópria para consumo, com emanação de odores desagradáveis, podendo gerar a mortalidade de peixes. Também pode ocorrer a desvalorização de imóveis localizados próximos ao reservatório e aumento da biomassa no leito.

A pesca também pode ser afetada de acordo com Agostinho, Gomes \& Pelicice (2007) visto que existe a baixa taxa de reprodução das espécies, causada pela mudança no ambiente; as mudanças bruscas no nível de água do reservatório ocorridas pelos procedimentos operacionais e; o elevado empenho de pesca aplicado no período de maior produtividade. Assim, depois do período de alto rendimento, ocorre um decréscimo na produção pesqueira, afetando a vida socioeconômica de muitos na região.

A área do projeto também pode ser afetada por abalos sísmicos. Segundo Müller (1995), esse fator não influenciado pela pressão do peso da água do reservatório, mas pelo aumento da pressão hidrostática que é produzido pela água infiltrada que pode acabar diminuindo a resistência das rochas, quebrar camadas de rochas, alterar a estabilidade do substrato ou ate mesmo reativar antigas falhas geológicas.

Entretanto, o fator social ainda é pouco respeitado quando é escolhido um local para implantar uma nova usina hidrelétrica. De acordo com Müller (1995), o problema social maior ocorre durante a construção da usina quando ocorre a desapropriação da área e as pessoas são obrigadas a se realocarem em função de novas áreas disponíveis. Segundo Brack (2010), até o ano de 2010 mais de 30 mil pessoas já foram afetadas pela construção de barragens na bacia do Rio Uruguai e esse número ainda pode dobrar. Ainda de acordo com o mesmo autor, pessoas que perdem suas terras podem sofrer transtornos e podem entrar em estado depressivo pelo resto da vida.

No Brasil de acordo com o Relatório da Comissão Mundial de Barragens do ano de 2000, existem entre 40 e 80 milhões de pessoas afetadas diretamente e segundo estimativas do: "Movimento Atingidos por Barragens", mais de um milhão de pessoas já foram expulsas de suas terras em decorrência da instalação de novas usinas como Candonga em Minas Gerais, Sobradinho na Bahia e Jataizinho no Paraná. Segundo uma pesquisa de opinião pública realizada por alunos do primeiro ano da Escola Estadual Almirante Tamandaré, que 
ouviram 160 pessoas a fim de saberem a opinião dos moradores sobre a construção de uma usina hidrelétrica na região do Estado do Paraná tiveram como resultado que $74 \%$ é contra, $20 \%$ a favor e $6 \%$ não souberam responder.

Outros problemas apontados por Claret (2013) relacionados ao município de AltamiraPA onde foi construída a usina de Belo Monte. O município triplicou seu número de habitantes acarretando em problemas como falta de hospitais que possam atender todos os novos moradores, falta de serviços básicos como coleta de lixo e aumento do preço de alimentos e aluguéis devido à grande demanda. Outro problema está relacionado à prostituição e exploração sexual de menores.

Diante de tantos problemas apresentados anteriormente, Queiroz et al. (2013) aponta as pequenas centrais hidrelétricas como possível solução. Elas produzem menores quantidades de energia, mas geram também menores impactos e estes podem ser trabalhados mais facilmente. Segundo Nilton (2009), as pequenas centrais hidrelétricas têm efeitos positivos como produção de energia, retenção de água apenas na região, melhor potencial de água de potável reservada, aumento da produção de peixes. Porém Araújo et al. (2009) aponta que transferir a população para outras terras se torna um desafio visto que é bastante complexo encontrar a mesma quantidade de terra e com as mesmas características influenciando ainda assim no bem-estar das famílias.

\section{Metano e Outros Gases de Efeito Estufa}

A construção de usinas hidrelétricas pode colaborar permanentemente de forma negativa no ecossistema local e em alguns casos em ambientes vizinhos, influenciando em fatores locais como umidade relativa do ar, ciclo pluvial, temperatura, microclima local e evaporação. Quantificar todos os impactos gerados pela construção de uma usina hidrelétrica é bastante complexo visto que trabalhar com dados e estudos relacionados a ecossistema e clima ainda são difíceis e geram discussões no meio científico.

Outro processo que se inicia quando a represa é construída é a decomposição da matéria orgânica acumulada no fundo do reservatório por bactérias. As mesmas emitem metano durante o processo de quebra da matéria e esse metano posteriormente é liberado na atmosfera. Esse processo acontece com maior frequência em regiões tropicais onde a média de temperatura colabora para a ação das bactérias. De acordo com Azenha (2010) a energia obtida das hidrelétricas não é limpa e estima-se que aproximadamente $4 \%$ das alterações causadas no clima pelo homem é proveniente dos reservatórios das hidrelétricas. 
Para Gunkel (2009) e Fearnside (2012), mesmo sendo considerada formas de energia verde a energia gerada em usinas hidrelétricas por meio de seus reservatórios emitem grandes quantidades de gases do efeito estufa. Essas quantidades podem variar de acordo com a idade da barragem, localização geográfica, características especificas dos reservatórios como profundidade e tempo de retenção da água, vazão, entrada de nutrientes e posicionamento de vertedores e turbinas.

Segundo Barros et al. (2011) e Matthews et al. (2005), as barragens em locais tropicais emitem mais metano e outros gases em comparação às barragens localizadas em locais de clima temperado ou boreal. De acordo com Bastviken et al. (2011), o somatório de toda lâmina d'água dos reservatórios de todo mundo somam mais de $500.000 \mathrm{~km}^{2}$ e podem emitir por ano cerca de 20 milhões de toneladas de metano na atmosfera. Esses valores são estimados apenas para o metano que por fatores naturais emerge à superfície.

Para Abril et al. (2005), Fearnside (2008, 2009) e Kemenes et al. (2008), esses valores podem até dobrar se considerado o metano que estando sobre pressão nas camadas mais profundas de água do reservatório são liberados na atmosfera quando essa coluna d'água passa pelas turbinas ou vertedouros da usina. Outras emissões também ocorrem no inicio das obras da usina.

Quando se iniciam as obras da barragem o ambiente começa a ser alterado e o uso de combustível para máquinas, retirada da vegetação, aplicação de concreto e ferragens dão início às emissões de gases do efeito estufa. Tais emissões são superiores se comparadas as emissões em usinas solares, eólicas ou de combustíveis fósseis. Segundo Fearnside (2009), as emissões da construção da represa de Belo Monte foram estimadas em 0,98 milhões de toneladas de carbono equivalentes ao $\mathrm{CO} 2$ emitido e 0,78 milhões de toneladas na represa de Babaquara/Altamira.

\section{Considerações Finais}

Energia tem sido o principal propulsor econômico de todas as nações. Está bem claro que os países que conseguiram obter energia com menor custo e em maiores quantidades conseguiram se destacar perante os outros e se desenvolver de forma mais rápida. A energia tem sido o fator decisivo para o desenvolvimento. Até então não há nada errado. O problema tem sido na hora de escolher o tipo de energia a ser utilizada. Ora por fatores econômicos, ora por fatores naturais e até pela disponibilidade de recursos, alguns países têm utilizado formas de energia que agridem muito o meio ambiente. Porém, antes de qualquer argumentação é 
necessário avaliar quais fatores foram levados em conta na escolha do uso das diversas formas de energia disponíveis.

É certo que nenhuma forma de geração de energia é limpa, porém umas podem ser usadas preferencialmente em comparação com outras. Cabe a cada país definir sua matriz energética baseado em profundos estudos ambientais que visam minimizar os impactos que serão causados durante os processos e poder garantir o fornecimento de energia à população de forma garantida e barata.

\section{Referências}

Agostinho CS, Gomes LC \& Pelicice FM. (2007). Ecologia e manejo de recursos pesqueiros em reservatórios do Brasil. Maringá: Eduem.

Andrade A. (2010). O Papel das PCHs na economia Catarinense. Monografia (Bacharelado)

- Ciências Econômicas da Universidade Federal de Santa Catarina.

Araújo LE, Sousa ASS, Neto, JMM, Souto JS, Reinaldo LRLR. (2009). Impactos ambientais em bacias hidrográficas - Caso da Bacia do Rio Paraíba. Sistema Eletrônico de RevistasUEPB.

Azenha M. (2010). Célio Bermann e Belo Monte: “A energia hidrelétrica não é limpa, nem barata”. Disponível: https://www.viomundo.com.br/retratos/bermann-a-energia-hidreletricanao-e-limpa-nem-barata.html.

Bonsor K. (2016). Impactos ambientais na construção de hidrelétricas. Disponível em: <ciencia.hsw.uol.com.br/usinas-hidrelétricas>.

Bortoleto EM. (2001). A implantação de grandes hidrelétricas: desenvolvimento, discurso e impactos. Geografares, n. 2, jun.

Brack, P. (2014). Ofício/InGá/nº3/2014 protocolado no MPE. Porto Alegre. Disponível em: http://agapan.blogspot.com.br/2014/02/inga-questiona-ministerio-publico.html >. 
Brasil. (2015). Agência Nacional de Energia Elétrica. Atlas de energia elétrica do Brasil. Brasília: Aneel, 2008. p. 236p.BRASIL, Ministério de Minas e Energia. Resenha Energética Brasileira: Exercício de 2014. Brasília-DF. Disponível em: http://www.mme.gov.br/ documents/1138787/1732840/Resenha+Energ\%C3\%A9tica+-+Brasil+2015.pdf/4e6b9a346b2e-48fa-9ef8-dc7008470bf2.

Brasil. (2015). Projeção da demanda de energia elétrica para os próximos 10 anos (10152024). Rio de Janeiro. Disponível em: http://www.epe.gov.br/mercado/Documents/ DEA\%2003-2015-\%20Projeções\%20da\%20Demanda\%20de\%20Energia\%20Elétrica\% 202015-2024.pdf.

Breda LS. (2011). Avaliação espaço - temporal da qualidade da água do reservatório da usina hidrelétrica de Funil-Região Sul de Minas Gerais.

Campos FS. (1990). Estudo da variabilidade de precipitação. 36 f. Monografia (Trabalho de Conclusão de Curso) - Instituto Tecnológico da Aeronáutica, São José dos Campos.

Cardoso ETS. (2011). Avaliação do grau de trofia e da qualidade da água de um braço do reservatório de Itaipu - Brasil. 2011. 144 p. Dissertação de Mestrado. UFABC - Santo André.

Carvalho NO. (2000). Guia de Avaliação de Assoreamento de Reservatórios da Agência Nacional de Energia Elétrica - ANEEL. Brasília. 132p.

Claret A. (2013). Chegou o inv(f) erno. São Paulo: Outras Expressões, 160 p.

Colito MCE. (2000). A construção de usinas hidrelétricas e os impactos sobre a população e o espaço: comunidades rurais ameaçadas pela U.h. de Jataizinho - Rio Tibagi/Pr. Serviço Social em Revista. 2(2).

Correia MF \& Silva Dias MAF. (2000). Efeito do Lago de Sobradinho no clima local: uma análise numérica e observacional. In: XI Congresso Brasileiro de Meteorologia, 2000, Rio de Janeiro. Anais do XI Congresso Brasileiro de Meteorologia, 2000. p. 1739-48. 
Derrosso GS \& Ichikawa EY. (2014). A Construção de uma usina hidrelétrica e a reconfiguração das identidades dos ribeirinhos: um estudo em Salto Caxias, Paraná. Ambiente \& Sociedade, 17(3): 97-114. jul.-set.

Didonet M. (2009). Natureza da Paisagem: Energia: Recurso da Vida. Rio de Janeiro: CIMA.

Filho AV. (2018). Energia Elétrica no Brasil: Contexto Atual e Perspectivas. Disponível em: http://interessenacional.uol.com.br/index.php/edicoes-revista/energia-eletrica-no-brasilcontexto-atual-e-perspectivas/.

Fisch GF, Januário M \& Senna RC. (1990). Impacto ecológico em Tucuruí: climatologia. Acta Amazônica, 20(1).

Fisch GF, Marengo JA \& Nobre CA. (1998). Uma revisão geral do clima da Amazônia. Acta Amazônica, 28(2).

Kuniyoshi T. (2009). Least marginal environmental impact rule for reservoir development. Sciences Journal, 42(1): 583-97. London, UK. Disponível em: http://www.tandfonline.com/ doi/abs/10.1080/02626669709492055.

Limberg L. (2007). O clima do oeste do Paraná: análise da presença do lago de Itaipu. $136 \mathrm{f}$. Dissertação (Mestrado em Geografia) - Instituto de Geociências e Ciências Exatas, Universidade Estadual Paulista, Rio Claro.

Müller AC. (1995). Hidrelétricas, meio ambiente e desenvolvimento. São Paulo: Ed. Makron Books.

Müller C. (2003). Construção de hidrelétricas gera debate sobre impacto ambiental. Disponível em: http://ciclovivo.com.br/noticia/construcao-de-hidreletricas-gera-debatesobreimpacto-ambiental. 
Muniz LS \& Santos EC. (2012). A gestão participativa em estudos prévios de impacto ambiental de usinas hidroelétricas na Amazônia. Revista Geonorte, Manaus, 3(4): 12-23.

Nilton CL. (2009). O impacto das pequenas centrais hidrelétricas - Pchs no meio ambiente. Dissertação (Mestrado) - Programa de Pós Graduação Latu Sensu Formas Alternativas de Energia - Departamento de Engenharia da Universidade Federal de Lavras.

Oliveira CRO. (2004). Impactos ambientais em barragens. São Paulo, 85 f. Monografia (Graduação), Universidade Anhembi Morumbi.

Paquete S. (2018). Qual o impacto ambiental da instalação de uma hidrelétrica? Disponível em: https://super.abril.com.br/mundo-estranho/qual-o-impacto-ambiental-da-instalacao-deuma-hidreletrica/. Acesso em: 22. Abr. 2018.

Queiroz ARS. (2011). Análise dos impactos sociais de grandes empreedimentos hidrelétricos: o caso do AHE Belo Monte”. 74f. Dissertação (Mestrado). Escola Nacional de Saúde Pública, Sergio Arouca (ENSP), Fundação Oswaldo Cruz. Rio de Janeiro.

Queiroz R, Grassi P, Lazzare K, Koppe E, Tartas BR, Kemerich PDC. (2013). Geração de energia elétrica através da energia hidráulica e seus impactos ambientais. Revista Eletrônica em Gestão, Educação e Tecnologia Ambiental - REGET. e-ISSN 22361170 - 13(13), 277484. Ago.

Rosa LP, Sigaud L, La Rovere EL, Magrini A, Poole A \& Fearnside P. (1995). Estado, Energia Elétrica e Meio Ambiente: O Caso das Grandes Barragens. COOPE/UFRJ.

Sanches F \& Fisch G. (2005). As possíveis alterações microclimáticas devido a formação do lago artificial da hidrelétrica de Tucuruí-PA. Acta Amazônica, 35(1).

Silva, S. S. et al. (2007). Análise de impactos ambientais gerados pela construção de uma barragem na Bacia do Médio Una, Taubaté, SP. In: Seminário de Recursos Hídricos da Bacia Hidrográfica do Paraíba do Sul, Taubaté. Anais do I Seminário de Recursos Hídricos da Bacia Hidrográfica do Paraíba do Sul, 43-50. 
Siqueira JE, Henkes JA. (2014). Impactos gerados por represas de usinas hidrelétricas: o caso da usina hidrelétrica de Manso. Revista Gestão Sustentável e Ambiental, 3(1), abr./ set.

Soares VR. (2009). Impactos Sociais causados pela construção de hidrelétricas em populações ribeirinhas na zona da mata mineira: o caso específico da Usina Hidrelétrica Candonga - Rio Doce/Santa Cruz Escalvado - Minas Gerais. Monografia (Ciências Sociais) - Instituto de Ciências Humanas, Universidade Federal de Juiz de Fora, Juiz de Fora.

Souza MB. (2010). Influência de lagos artificiais no clima local e urbano: estudo de caso em Presidente Epitácio (SP). 204 f. Tese (Doutorado em Geografia Física) - Programa de PósGraduação em Geografia Física da Faculdade de Filosofia, Letras e Ciências Humanas, Universidade de São Paulo, São Paulo.

Sousa WL. (2000). Impacto Ambiental de Hidrelétricas: Uma Análise Comparativa de Duas Abordagens. Dissertação (Mestrado). Departamento de Planejamento Energético da Universidade Federal do Rio de Janeiro.

Thaumaturgo LRY, Simões SJC, Trannin ICB. (2013). A construção da usina hidrelétrica de Itaipu e seu impacto sobre a urbanização de Foz do Iguaçu. In: XVI Simpósio Brasileiro de Sensoriamento Remoto - SBSR, Foz do Iguaçu, Anais... Foz do Iguaçu. P 983-90. Disponível em: http://www.dsr.inpe.br/sbsr2013/files/p1519.pdf.

Wolfgang JJ \& Mello, JASN. (1990). Impactos ecológicos das represas hidrelétricas na bacia amazônica brasileira. Instituto de Estudos Avançados da Universidade de São Paulo. Disponível em: http://www.scielo.br/scielo.php?pid=S0103-40141990000100010\&script=sci -arttext.

\title{
Porcentagem de contribuição de cada autor no manuscrito
}

\author{
Ramon de Souza Ferreira - 100\%
}

